Original Article

\title{
Comparison of Effects of Supervised Physiotherapy and a Standardized Home Program on Functional Status in Patients with Total Knee Arthroplasty: A Prospective Study
}

\author{
Nihal BüKer 1)*, Semih Akkaya ${ }^{2)}$, Nuray Akkaya ${ }^{3)}$, OĞuzhan GöKalp, MD²),

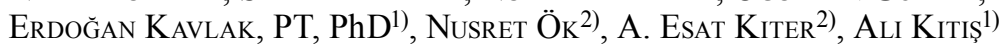 \\ 1) School of Physical Therapy and Rehabilitation, Pamukkale University: High School Building, Z \\ Floor, Kinıklı Campus, Denizl, Turkey \\ 2) Department of Orthopedics, Faculty of Medicine, Pamukkale University, Turkey \\ 3) Department of Physical Medicine, Faculty of Medicine, Pamukkale University, Turkey
}

\begin{abstract}
Purpose] The aim of this study was to determine the functional differences between total knee arthroplasty (TKA) patients who were treated with supervised physiotherapy or a standardized home program and perform a cost analysis. [Subjects and Methods] Patients who received total knee arthroplasty between January 2009 and June 2011 were enrolled in this study; those with mean ages of $64.25 \pm 3.86(60-68)$ years $(n=18)$ and $68.08 \pm 6.25$ (61-79) years $(n=16)$ were placed in the supervised physiotherapy and standardized home program groups, respectively. All patients were evaluated by the same researcher before and after surgery, and the therapy programs were applied by another physiotherapist. All patients were evaluated for joint range of motion (ROM), pain, functional status (WOMAC), overall quality of life (SF-36), and depressive symptoms (BECK Depression Scale). [Results] A significant clinical improvement was observed in postoperative assessments. A statistically significant difference could not be found between ROM and functional levels of the patients in both groups. [Conclusion] No difference was found between the patients performing supervised or standardized home program with respect to the effects on functional status. A home exercise program can be used in the rehabilitation of patients with TKA, and implementation of home exercise programs can also reduce health-care spending.

Key words: Total knee replacement, Rehabilitation, General health status
\end{abstract}

(This article was submitted Feb. 26, 2014, and was accepted Mar. 31, 2014)

\section{INTRODUCTION}

Gonarthrosis is one of the most common arthrotic involvements developing due to a degenerative process in the skeletal system ${ }^{1)}$. It is not possible to stop the degenerative process despite the presence of many treatment alternatives. The total knee arthroplasty is the gold standard ${ }^{2}$ for reducing pain, healing deformities and restoring stability in patients who progress to the terminal stage ${ }^{2-4)}$.

Arthroplasty is a commonly accepted treatment method in degenerative diseases of the knee and the hip with excellent outcomes shown in the last $15-20$ years ${ }^{5,6)}$. Components of motion of knee joint are hurt from in arthroplasty applications as in every operation affecting skeletal system. Physiotherapy techniques are the most important tools that patients and doctors have for rapidly regaining functional

*Corresponding author. Nihal Büker (E-mail: nasuk@, pau.edu.tr)

(C2014 The Society of Physical Therapy Science. Published by IPEC Inc. This is an open-access article distributed under the terms of the Creative Commons Attribution Non-Commercial No Derivatives (by-ncnd) License $<$ http://creativecommons.org/licenses/by-nc-nd/3.0/>. status. Rehabilitation programs including supervised physical therapy ${ }^{7}$ ) or home exercises are recommended for restoring functional status in patients after knee arthroplasty ${ }^{8,9)}$. Supervised physical therapy two or three times a week is a common method of achieving this goal ${ }^{7)}$.

Recently, interest has been increasing regarding investigation and evaluation of the causes of increasing health $\operatorname{costs}^{10)}$. Effort has been focused on studies about cost-effectiveness analysis and controlling costs ${ }^{11}$. Increased cost of health care leads to critical investigations concerning the effectiveness of treatment and needs in physiotherapy and rehabilitation methods. Therefore, some studies have focused on home exercises ${ }^{8,9)}$.

These types of analyses are required for health costs in our country. The main purpose of this study was to prospectively compare the short- and long-term outcomes of supervised physiotherapy and a standardized home program following discharge of patients who underwent TKA and to evaluate the effectiveness and costs of postoperative rehabilitation.

\section{SUBJECTS AND METHODS}

This study was conducted in accordance with the prin- 
ciples of the Helsinki Declaration (2008). It was conducted after ethics committee approval had been obtained from the Pamukkale University Medical Faculty (Ref no.08, date: 28.05.2013).

Patients who underwent total knee arthroplasty between January 2009 and June 2011 were randomly divided to two groups, a supervised physiotherapy (SP) group and standardized home program (HP) group, using a random number table.

Surgical opening, the arthroplasty technique (extramedullary guide, ligament-preserving type of arthroplasty, etc.), incision closure and wound care were performed in a standard manner in all patients.

The same treatment program was applied to all patients during their hospitalizations. All patients were mobilized after their drainage tubes had been removed postoperatively, and a continuous passive motion (CPM) device was applied beginning with 45 degrees of knee flexion and continuing with 60 degrees on day 2, 90 degrees on day 3 and 110 degrees on days 4 and 5. Strengthening exercises were applied for the thigh abductor, adductor, extensor and quadriceps femoris muscles with active aid, and active joint motions twice daily under supervision of the physiotherapist until discharge from the hospital. Patients were mobilized with a walker so that they could bear as much weight as was tolerable on the arthroplasty side 24 hours after the operation. They also received training for moving up and down stairs before hospital discharge.

After discharge, patients in the home program were controlled for exercises once weekly for 4 weeks and rearranged by the physiotherapist when needed. Patients (home program group) performed home exercise for an hour a day, five days a week, for four weeks. Home exercises included arrangement of knee joint motion limit, restoration of knee and hip muscle power. Patients in supervised physiotherapy participated in a total of 20 sessions of a physiotherapy and rehabilitation program 5 days a week for 4 weeks. This program included knee joint range of motion (ROM) exercises and strengthening exercises for the knee and hip following 20 min of application of moist heat, and 20 min of conventional transcutaneal electrical nerve stimulation (TENS) application.

All participants were evaluated by a different physiotherapist, that is, not the one applying the therapy program.

Descriptive data of the participants were collected using a descriptive data questionnaire. A $10 \mathrm{~cm}$ Visual Analogue Scale consisting of a straight vertical line was used to grade pain. The patients were instructed that " 0 " represented "no pain" and that " 10 " represented "the most severe pain". The Patients were then asked to mark their level of pain on the line, and the distance to the point they marked was measured using a ruler and recorded ${ }^{12}$.

Range of Motion (ROM) was evaluated using a universal goniometer, and measurements were evaluated using the ROM degrees defined by Kendall ${ }^{13)}$.

The Western Ontorio and McMaster Universities Osteoarthritis Index (WOMAC) was used for assessment of functional status. The reliability and validity of the Turkish index composed of 24 questions were tested by Tüzün et al. in 2005 ${ }^{14)}$. The index was scored on Likert scale ranging between 0 and 4, with " 0 " indicating "no" and "4" indicating "very severe". The results were evaluated out of 100 points, with " 100 " meaning "healthy" and " 0 " meaning "very poor"15).

The Beck Depression Inventory Scale was used for assessment of depression. This scale targets identification of the severity of depression rather diagnosis of depression. The reliability and validity of the Turkish adaptation of the scale were tested by Hisli et al., and the cutoff value was determined to be $17^{16)}$. Patients were asked to answer the questions on their own.

The Short Form 36 (SF-36), which was developed by the Rand Corporation, was used for assessment of overall quality of life ${ }^{17)}$. A study of the reliability and validity of the Turkish scale has been performed. The scale is composed of 36 items measuring 8 dimensions. The subscales are used to evaluated health by transforming them to scales ranging between $0-100$, with " 0 " indicating "poor health" and "100" indicating a "good health status". These subscales are reported to be usable for assessment of quality of life in patients who have physical diseases ${ }^{18)}$. Patient were asked to complete the scale on their own.

The Statistical Package for the Social Sciences (SPSS) version 16.0 was used for statistical analysis. Descriptive statistical data are presented as means \pm standard deviation $(\mathrm{x} \pm \mathrm{SD})$ or percentages $(\%)$. A $\mathrm{p}$ level of $\leq 0.05$ was accepted as statistically significant and interpreted. The Kolmogorov-Smirnov test was used to determine whether data met parametric test conditions. The superiority of the demographic data obtained before the study was evaluated with the independent samples t-test in independent groups. The paired samples t-test was applied in dependent groups to determine the effectiveness of the methods used in the study. The independent samples t-test was used to determine the superiority of applications in independent groups ${ }^{19}$.

\section{RESULTS}

The mean age of the patients was $64.25 \pm 3.86$ years in the SP group and $68.08 \pm 6.25$ years in the HP group. Other descriptive data of the patients are given in Table 1 .

Clinical improvements were observed in postoperative assessments in both groups. Data recorded in different control periods are given in Table 2 for the SP group and in Table 3 for the HP group.

While there was not a statistically significant difference in activity pain of the patients in both groups, assessments of resting pain were found to be statistically significantly different in month $3(\mathrm{p}=0.032)$ and after 2 years $(\mathrm{p}=0.00)$ in favor of the HP group. No statistically significant difference was detected at each assessment point when ROM and functional status of the patients were compared. When depressive symptoms of the patients in both groups were compared at different assessment points, a statistically significant difference was detected in the HP group in only the month 6 assessments $(p=0.000)$. When the overall qualities of life of the patients were compared, a statistically significant difference was detected in favor of the HP group in all 
Table 1. Descriptive data of the patients

\begin{tabular}{lcccc}
\hline \multirow{2}{*}{ Variables } & \multicolumn{3}{c}{ Supervised physiotherapy group } & \multicolumn{2}{c}{$\begin{array}{c}\text { Standardized home program group } \\
(\mathrm{n}=16)\end{array}$} \\
\cline { 2 - 5 } & Min-Max & $\mathrm{X} \pm \mathrm{SD}$ & Min-Max & $\mathrm{X} \pm \mathrm{SD}$ \\
\hline Age (years) & $60-68$ & $64.25 \pm 3.86$ & $61-79$ & $68.08 \pm 6.25$ \\
Height $(\mathrm{cm})$ & $154-158$ & $155.75 \pm 1.70$ & $155-168$ & $161.17 \pm 3.35$ \\
Weight $(\mathrm{kg})$ & $66-104$ & $85.75 \pm 17.01$ & $50-103$ & $74.83 \pm 13.81$ \\
BMI $\left(\mathrm{kg} / \mathrm{m}^{2}\right)$ & $26.44-43.85$ & $35.44 \pm 7.60$ & $19.53-40.62$ & $28.81 \pm 5.37$ \\
Educational status $(\mathrm{yr})$ & $5-5$ & $5.00 \pm 0.00$ & $0-12$ & $3.91 \pm 3.50$ \\
& $\mathrm{n}$ & $\%$ & $\mathrm{n}$ & $\%$ \\
Gender* & 16 & 88.9 & 15 & \\
Female & 2 & 11.1 & 1 & 93.8 \\
Male & & & & 6.2 \\
Job* & 16 & 88.9 & 15 & 93.8 \\
Housewife & 1 & 5.6 & 1 & 6.2 \\
Self-employed & 1 & 5.6 & - & - \\
Retired teacher & & & & \\
\hline
\end{tabular}

*Statistically significant $(\mathrm{p}<0.05)$

Table 2. Comparison of outcomes before and after the operation in supervised physiotherapy group

\begin{tabular}{|c|c|c|c|c|c|c|}
\hline \multirow{3}{*}{ Variables } & \multicolumn{5}{|c|}{ Supervised physiotherapy group $(\mathrm{n}=18)$} & \multirow{3}{*}{ Results causing differences } \\
\hline & $\begin{array}{l}\text { Before the } \\
\text { operation }\end{array}$ & $3 \mathrm{mo}$ & $6 \mathrm{mo}$ & 1 year & 2 years & \\
\hline & $\mathrm{X} \pm \mathrm{Ss}$ & $\mathrm{X} \pm \mathrm{Ss}$ & $\mathrm{X} \pm \mathrm{Ss}$ & $\mathrm{X} \pm \mathrm{Ss}$ & $\mathrm{X} \pm \mathrm{Ss}$ & \\
\hline \multicolumn{7}{|l|}{ Pain (VAS) } \\
\hline Rest & $5.30 \pm 2.95$ & $0.33 \pm 0.59$ & $0.00 \pm 0.00$ & $0.44 \pm 0.51$ & $1.11 \pm 0.47$ & $1-2,1-3,1-4,1-5,2-4,3-4,3-5,4-5$ \\
\hline Activity & $9.25 \pm 0.94$ & $1.83 \pm 1.50$ & $1.77 \pm 2.39$ & $3.11 \pm 1.96$ & $0.83 \pm 0.78$ & $1-2,1-3,1-4,1-5,4-5$ \\
\hline \multicolumn{7}{|l|}{$\operatorname{ROM}\left({ }^{\circ}\right)$} \\
\hline Flexion & $72.38 \pm 28.95$ & $85.27 \pm 7.37$ & $108.83 \pm 15.26$ & $102.50 \pm 9.88$ & $112.78 \pm 3.07$ & $1-3,1-4,1-5,2-3,2-5,4-5$ \\
\hline Extension & $-16.33 \pm 9.71$ & $-2.72 \pm 2.88$ & $-3.33 \pm 7.66$ & $-2.77 \pm 4.60$ & $0.38 \pm 1.64$ & $1-2,1-3,1-4,1-5,2-5$ \\
\hline Functional status (WOMAC) & $67.38 \pm 13.15$ & $27.27 \pm 15.58$ & $15.38 \pm 7.22$ & $17.72 \pm 17.51$ & $6.22 \pm 6.89$ & $1-2,1-3,1-4,1-5,2-5,3-5,4-5$ \\
\hline Beck depression scale & $16.44 \pm 9.85$ & $7.50 \pm 2.50$ & $9.22 \pm 1.43$ & $9.44 \pm 6.83$ & $6.16 \pm 3.27$ & $1-2,1-5,3-5$ \\
\hline \multicolumn{7}{|c|}{ Overall quality of life scale (SF-36) } \\
\hline Overall health status & $45.61 \pm 22.30$ & $77.83 \pm 6.11$ & $55.83 \pm 26.80$ & $32.50 \pm 23.5$ & $52.77 \pm 22.30$ & $1-2,2-3,2-4,2-5$ \\
\hline Physical status & $15.72 \pm 14.38$ & $42.77 \pm 15.07$ & $63.05 \pm 16.63$ & $55.55 \pm 23.19$ & $74.72 \pm 14.59$ & $1-2,1-3,1-4,1-5,2-3,2-5$ \\
\hline Emotional status & $56.22 \pm 23.82$ & $60.18 \pm 15.05$ & $50.20 \pm 18.31$ & $51.22 \pm 16.24$ & $74.22 \pm 7.90$ & $2-5,3-5,4-5$ \\
\hline Social status & $51.22 \pm 28.83$ & $47.16 \pm 10.89$ & $68.61 \pm 16.01$ & $54.83 \pm 23.88$ & $82.50 \pm 8.17$ & $1-5,2-3,2-5,4-5$ \\
\hline Physical role limitation & $1.38 \pm 5.89$ & $11.10 \pm 32.33$ & $0.00 \pm 0.00$ & $44.44 \pm 51.13$ & $77.78 \pm 37.26$ & $1-4,1-5,2-5,3-4,3-5$ \\
\hline Emotional role limitation & $33.44 \pm 45.70$ & $58.77 \pm 29.14$ & $27.56 \pm 36.35$ & $77.78 \pm 42.77$ & $94.43 \pm 23.57$ & $1-5,2-5,3-4,3-5$ \\
\hline Pain & $16.72 \pm 16.68$ & $53.16 \pm 6.41$ & $59.01 \pm 12.68$ & $65.72 \pm 33.63$ & $63.47 \pm 15.07$ & $1-2,1-3,1-4,1-5$ \\
\hline Energy level & $44.55 \pm 27.67$ & $53.33 \pm 5.68$ & $52.22 \pm 3.91$ & $40.55 \pm 23.63$ & $71.66 \pm 10.98$ & $1-5,2-5,3-5,4-5$ \\
\hline
\end{tabular}

*Variance analysis in repeated measurements

$1=$ before the operation

$2=3$ months after the operation

$3=6$ months after the operation

$4=1$ year after the operation

$5=1$ year after the operation

subparameters except emotional status, physical role limitation, pain, and energy level in month 3 and in all subparameters except physical status and social status in month 6. A statistically significant difference was detected in favor of the HP group in all subparameters except physical status, emotional role limitation, and pain after 1 year, and a sig- nificant difference was detected in favor of the HP group in physical status and social status and in favor of the SP group in emotional role limitation, pain, and overall quality of life parameters (Table 4).

A cost analysis was performed for physical therapy and rehabilitation services following TKA. The total costs were 
1534 J. Phys. Ther. Sci. Vol. 26, No. 10, 2014

Table 3. Comparison of developments before and after the operation in home exercise program

\begin{tabular}{|c|c|c|c|c|c|c|}
\hline \multirow{3}{*}{ Variables } & \multicolumn{5}{|c|}{ Standardized home program group $(\mathrm{n}=16)$} & \multirow{3}{*}{$\begin{array}{c}\text { Measurements causing } \\
\text { differences }\end{array}$} \\
\hline & $\begin{array}{l}\text { Before the } \\
\text { operation }\end{array}$ & $3 \mathrm{mo}$ & $6 \mathrm{mo}$ & 1 year & 2 years & \\
\hline & $\mathrm{X} \pm \mathrm{SD}$ & $\mathrm{X} \pm \mathrm{SD}$ & $\mathrm{X} \pm \mathrm{SD}$ & $\mathrm{X} \pm \mathrm{SD}$ & $\mathrm{X} \pm \mathrm{SD}$ & \\
\hline \multicolumn{7}{|l|}{ Pain (VAS) } \\
\hline Rest & $5.15 \pm 3.84$ & $0.00 \pm 0.00$ & $0.12 \pm 0.34$ & $0.37 \pm 0.80$ & $0.00 \pm 0.00$ & $1-2,1-3,1-4,1-5$ \\
\hline Activity & $7.96 \pm 3.09$ & $1.68 \pm 1.53$ & $0.56 \pm 0.75$ & $2.50 \pm 1.77$ & $1.00 \pm 0.00$ & $1-2,1-3,1-4,1-5,3-4,4-5$ \\
\hline \multicolumn{7}{|l|}{$\operatorname{ROM}\left({ }^{\circ}\right)$} \\
\hline Flexion & $92.68 \pm 18.00$ & $90.12 \pm 10.65$ & $106.91 \pm 12.74$ & $103.12 \pm 20.64$ & $113.75 \pm 9.39$ & $1-5,2-3,2-5$ \\
\hline Extension & $-13.25 \pm 15.77$ & $-1.56 \pm 2.39$ & $-0.62 \pm 1.70$ & $-1.87 \pm 4.03$ & $0.00 \pm 0.00$ & $1-3,1-5$ \\
\hline Functional status (WOMAC) & $54.87 \pm 14.93$ & $25.00 \pm 14.05$ & $15.62 \pm 11.34$ & $11.25 \pm 9.39$ & $6.62 \pm 6.06$ & $1-2,1-3,1-4,1-5,2-3,2-4,2-5,3-4,3$ \\
\hline Beck depression scale & $11.12 \pm 5.87$ & $7.18 \pm 5.29$ & $5.50 \pm 3.14$ & $5.75 \pm 5.54$ & $4.50 \pm 5.66$ & $1-3,1-5$ \\
\hline \multicolumn{7}{|c|}{ Overall quality of life scale (SF-36) } \\
\hline Overall health status & $59.68 \pm 19.36$ & $78.18 \pm 6.15$ & $73.43 \pm 15.24$ & $64.37 \pm 17.40$ & $64.06 \pm 12.80$ & $1-2,2-4,2-5$ \\
\hline Physical status & $28.75 \pm 14.77$ & $49.37 \pm 27.50$ & $74.37 \pm 23.37$ & $71.25 \pm 25.26$ & $85.93 \pm 2.80$ & $1-3,1-4,1-5,2-5$ \\
\hline Emotional status & $60.25 \pm 14.71$ & $87.01 \pm 17.00$ & $81.25 \pm 10.90$ & $63.02 \pm 19.18$ & $74.75 \pm 6.14$ & $1-2,1-3,1-5,2-4,3-4$ \\
\hline Social status & $61.37 \pm 29.54$ & $48.12 \pm 18.50$ & $75.56 \pm 25.72$ & $81.81 \pm 20.28$ & $88.59 \pm 1.28$ & $1-5,2-4,2-5$ \\
\hline Physical role limitation & $0.00 \pm 0.00$ & $62.50 \pm 50.00$ & $71.87 \pm 40.69$ & $87.50 \pm 34.15$ & $57.81 \pm 38.42$ & $1-2,1-3,1-4,1-5$ \\
\hline Emotional role limitation & $12.43 \pm 29.40$ & $62.49 \pm 51.00$ & $81.12 \pm 29.90$ & $87.51 \pm 34.15$ & $62.50 \pm 34.15$ & $1-2,1-3,1-4,1-5$ \\
\hline Pain & $23.12 \pm 18.46$ & $43.87 \pm 1.50$ & $73.40 \pm 24.40$ & $52.06 \pm 17.56$ & $54.21 \pm 3.84$ & $1-2,1-3,1-4,1-5,2-3,2-5$ \\
\hline Energy level & $48.43 \pm 18.04$ & $63.12 \pm 2.50$ & $65.62 \pm 16.21$ & $56.25 \pm 16.58$ & $68.43 \pm 7.68$ & $1-3,1-5$ \\
\hline $\begin{array}{l}* \text { Variance analysis in repeat } \\
1=\text { before the operation } \\
2=3 \text { months after the operat } \\
3=6 \text { months after the operat } \\
4=1 \text { year after the operation } \\
5=1 \text { year after the operation }\end{array}$ & $\begin{array}{l}\text { ated measureme } \\
\text { ation } \\
\text { ation } \\
\text { n } \\
\text { n }\end{array}$ & ents & & & & \\
\hline
\end{tabular}

Table 4. Differences between supervised physiotherapy and the standardized home program

\begin{tabular}{lccccc}
\hline \multirow{2}{*}{ Variables } & $\begin{array}{c}\text { Before the } \\
\text { operation }\end{array}$ & 3 mo & 6 mo & 1 year & 2 years \\
\cline { 2 - 5 } & $\mathrm{t}$ & $\mathrm{t}$ & $\mathrm{t}$ & $\mathrm{t}$ & $\mathrm{t}$ \\
\hline Pain (VAS) & & & & & \\
$\quad$ Rest & 0.128 & $2.240^{*}$ & -1.556 & 0.303 & $9.412^{*}$ \\
$\quad$ Activity & 1.676 & 0.279 & 1.948 & 0.945 & -0.847 \\
ROM( ${ }^{\circ}$ ) & & & & \\
Flexion & $-2.417^{*}$ & -1.558 & 0.397 & -1.331 & -0.415 \\
$\quad$ Extension & -0.695 & -1.266 & -1.380 & -0.604 & 0.941 \\
Functional status (WOMAC) & $2.589^{*}$ & 0.441 & -0.073 & 1.317 & -0.180 \\
Beck depression scale & 1.880 & -0.015 & $0.019^{*}$ & 0.041 & 1.064 \\
Overall quality of life scale (SF-36) & & & & & \\
Overall health status & -1.953 & -0.168 & $-2.313^{*}$ & $-4.491^{*}$ & -1.778 \\
Physical status & $-2.602^{*}$ & -0.881 & -1.641 & -1.889 & $-2.364^{*}$ \\
Emotional status & -0.584 & $-5.684^{*}$ & $-5.904^{*}$ & $-2.103^{*}$ & -0.215 \\
Social status & -1.013 & -0.187 & -0.957 & $-3.526^{*}$ & $-2.943^{*}$ \\
Physical role limitation & -0.941 & $-3.599^{*}$ & $-7.508^{*}$ & $-2.848^{*}$ & 1.537 \\
Emotional role limitation & 1.571 & -2.269 & $-4.656^{*}$ & -0.726 & $3.204^{*}$ \\
Pain & -1.062 & $5.653^{*}$ & $-2.196^{*}$ & 1.456 & $2.383^{*}$ \\
Energy level & -0.478 & $-6.354^{*}$ & $-3.403^{*}$ & $-2.214^{*}$ & 0.981 \\
\hline
\end{tabular}

*Statistically significant $(\mathrm{p}<0.05)$, independent samples t-test 
Table 5. Cost analysis of physiotherapy and rehabilitation treatments in the physiotherapy and home program groups (based on 2013 Health Practices Notification prices)

\begin{tabular}{lcc}
\hline Applications & $\begin{array}{c}\text { Physiotherapy } \\
\text { group (TL) }\end{array}$ & $\begin{array}{c}\text { Home program } \\
\text { group (TL) }\end{array}$ \\
\hline Preoperative assessment & 15.50 & 15.50 \\
Weekly postoperative control & - & $93.00(15.50 \times 6)$ \\
Assessment at 1 month post operation & 15.50 & 15.50 \\
Physical therapy outpatient clinic examination & 15.50 & 15.50 \\
Physical therapy outpatient clinic assessment & 15.50 & 15.50 \\
Treatment parameters & & \\
Warm heat application & 2.40 & - \\
TENS application & 2.40 & - \\
ROM exercises & 4.80 & 4.80 \\
Progressive resistance exercises & 3.60 & 3.60 \\
Total price of the session & $264(13.20 \times 20)$ & $50.40(8.40 \times 6)$ \\
Outpatient clinic examination after 10 sessions & 15.50 & - \\
Outpatient clinic examination after 20 sessions & 15.50 & - \\
Assessment at 3 months post operation & 15.50 & 15.50 \\
Assessment at 6 months post operation & 15.50 & 15.50 \\
Assessment at 1 year post operation & 15.50 & 15.50 \\
Assessment at 2 years post operation & 15.50 & 15.50 \\
Transportation fee (round trip) & $89.60(3.20 \times 28)$ & $32.00(3.20 \times 10)$ \\
Total cost & 508.60 & 299.40 \\
\hline TENS: transcutaneous electrical nerve stimulation & & \\
TL: Turkish Lira & & \\
\end{tabular}

508.6 TL for the SP group and 299.40 TL for the HP group. The home exercise program reduced spending for health (physiotherapy and rehabilitation applications) (Table 5).

\section{DISCUSSION}

Total knee arthroplasty (TKA) is a quite effective method for treatment of knees with severe degenerative arthritis not treated with other treatment methods ${ }^{20)}$, and the number of patients undergoing TKA has been gradually increasing in our country as in other countries throughout the world in recent years ${ }^{21)}$.

Physical limitations arising with surgical intervention are similar in knee surgeries. Surgeons direct their patients to physiotherapy following surgical intervention due to loss of motion of the joint, accessory movement, quadriceps muscle atrophy, tissue edema, and walking, stability, pain, balance, and functional limitations ${ }^{22,23)}$. Physiotherapy and rehabilitation are usually recommended to help patients become functionally independent following knee surgery and to help them return to their pre-disease conditions. Supervised physiotherapy two or three times weekly is a commonly preferred method of achieving these goals ${ }^{7,24)}$. Today, the increased cost of health care and the sector becoming open to competition naturally increase the interest of economists and politicians in cost analysis, and cost-effectiveness calculations have begun to be performed for every application in health ${ }^{25)}$. Cost-effectiveness studies for evaluation and determination of the causes of increasing costs play an effective role in controlling expenditures $\left.{ }^{10,} 12,26\right)$. Increased health-care costs bring critical analysis for cost-effectiveness in physiotherapy applications together. Some studies have focused on home exercise, and home exercises have been shown to be as effective as supervised physical ther$a^{a p y}{ }^{8}$. There has been no study in our country determining the needs for physiotherapy and rehabilitation following hospital discharge after TKA, comparing supervised physiotherapy and rehabilitation and standardized home programs, and performing cost analyses fort he programs. Therefore, we planned to compare the functional outcomes and costs of a standardized home program and supervised physiotherapy.

While many studies are available in the literature comparing supervised rehabilitation and a standardized home program following anterior crucial ligament repair, there are very few studies about TKA. The available studies indicate that there is no significant difference between patients treated with supervised physiotherapy and those treated with a standardized home exercise program with respect to range of motion of the knee joint, functional status of the patient, and overall health status of the patient ${ }^{8,27,28)}$. In our study, this comparison was performed for patients who were followed up for a minimum of 2 years prospectively. While a statistically significant difference was not detected in most of the parameters, a significant difference was detected in some parameters in different assessment periods in favor of the HP group, and there was only a statistically significant difference in favor of the SP group in the emotinal role limitation and pain subparameters of the overall quality of life scale, but only at the 2-year assessments. In 
the assessments, statistically significant differences were usually observed between the two groups in the overall quality of life subscales. These differences may have arisen from the perceptions of the patients. Such differences in the 2 years assessments seems insignificant.

The cost analysis performed in the present study was based on the Health Practices Notification (HPN) published by Social Security Institution in 2013. The total cost of rehabilitation was determined to be $508.60 \mathrm{TL}$ in the SP group and 299.40 TL in the HP group according to official prices of the HPN. The cost of treatment in the SP group was almost twice that in the HP group, although there was no difference between the treatment applications in terms of outcome even though there was a significant difference in favor of the HP group in some parameters.

Patients with TKA experience some difficulties when they benefit from physical therapy and rehabilitation outpatient clinic services. In addition, delay of treatment due to crowded clinics and inadequate physical conditions leads to delays in rehabilitation programs for patients and loss of motivation in patients. Considering the economic burden of health care, we consider that it would be sufficient to instruct patients on how to perform a well-planned home exercise program and to have a physiotherapist perform regular follow-ups.

\section{REFERENCES}

1) Zhang Y, Xu L, Nevitt MC, et al.: Comparison of the prevalence of knee osteoarthritis between the elderly Chinese population in Beijing and whites in the United States: The Beijing Osteoarthritis Study. Arthritis Rheum, 2001, 44: 2065-2071. [Medline] [CrossRef]

2) Rankin EA, Alarcon GS, Chang RW, et al. NIH Consensus Panel: NIH Consensus Statement on total knee replacement December 8-10, 2003. J Bone Joint Surg Am, 2004, 86-A: 1328-1335. [Medline]

3) Callahan CM, Drake BG, Heck DA, et al.: Patient outcomes following tricompartmental total knee replacement. A meta-analysis. JAMA, 1994 271: 1349-1357. [Medline] [CrossRef]

4) Jones CA, Beaupre LA, Johnston DW, et al.: Total joint arthroplasties: current concepts of patient outcomes after surgery. Rheum Dis Clin North Am, 2007, 33: 71-86. [Medline] [CrossRef]

5) Van Herck P, Vanhaecht K, Deneckere S, et al.: Key interventions and outcomes in joint arthroplasty clinical pathways: a systematic review. J Eval Clin Pract, 2010, 16: 39-49 [CrossRef]. [Medline]

6) National Hospital Discharge Survey 1998-2005. US Department of Health \& Human Services CfDCaP. National Center for Health Statistics, 2006.

7) Wheatley WB, Krome J, Martin DF: Rehabilitation programmes following arthroscopic meniscectomy in athletes. Sports Med, 1996, 21: 447-456.
[Medline] [CrossRef]

8) Rajan RA, Pack Y, Jackson H, et al.: No need for outpatient physiotherapy following total knee arthroplasty: a randomized trial of 120 patients. Acta Orthop Scand, 2004, 75: 71-73. [Medline] [CrossRef]

9) Schenck RC Jr, Blaschak MJ, Lance ED, et al.: A prospective outcome study of rehabilitation programs and anterior cruciate ligament reconstruction. Arthroscopy, 1997, 13: 285-290. [Medline] [CrossRef]

10) Andrews M: America's best health plans. Desperate to control healthcare costs, employer are rolling out wellness programs with teeth. US News World Rep, 2007, 143: 55-56, 58, 60. [Medline]

11) Galvin RS, Delbanco S: Between a rock and a hard place: understanding the employer mind-set. Health Aff (Millwood), 2006, 25: 1548-1555. [Medline] [CrossRef]

12) Huskisson EC: Visual Analogue Scales. In: Pain Measurement and Assessment. Ed's, Melzack R, New York: Raven Press, 1983, pp 33-40.

13) Otman AS, Demirel H, Sade A: Tedavi Hareketlerinde Temel Değerlendirme prensipleri. Ankara, 1995, pp 58-73.

14) Tüzün EH, Eker L, Aytar A, et al.: Acceptability, reliability, validity and responsiveness of the Turkish version of WOMAC osteoarthritis index. Osteoarthritis Cartilage, 2005, 13: 28-33. [Medline] [CrossRef]

15) Bellamy N: WOMAC: a 20-year experiential review of a patient-centered self-reported health status questionnaire. J Rheumatol, 2002, 29: $2473-$ 2476. [Medline]

16) Hisli N: Beck Depresyon Envanterinin Üniversite Öğrencileri İçin Geçerliliği, Güvenirliği. Turk Psikoloji Dergisi, 1989, 7: 3-13.

17) Ware JE Jr, Sherbourne CD: The MOS 36 -item short-form health survey (SF-36). I. Conceptual framework and item selection. Med Care, 1992, 30: 473-483. [Medline] [CrossRef]

18) Koçyiğit H, Aydemir Ö, Ölmez N, et al.: KF-36 nın Türkçe için güvenilirliği ve geçerliliği. Ege Fizik Tedavi ve Rehabilitasyon Dergisi, 1999.

19) Kalaycı Ş: SPSS Uygulamalı Çok Değişkenli İstatistik Teknikleri, Asil Yayın Dağıtım: Ankara, 2009.

20) Hungerford DS, Krackow KA: Total joint arthroplasty of the knee. Clin Orthop Relat Res, 1985, 192: 23-33. [Medline]

21) Akgün I, Oğüt T, Kesmezacar H, et al.: [Total knee arthroplasty: a 4.5-year follow-up]. Acta Orthop Traumatol Turc, 2002, 36: 93-99. [Medline]

22) Coppola SM, Collins SM: Is physical therapy more beneficial than unsupervised home exercise in treatment of post surgical knee disorders? A systematic review. Knee, 2009, 16: 171-175. [Medline] [CrossRef]

23) Park D, Kim J, Lee H, et al.: Effectiveness of modified quadriceps femoris muscle setting, exercise for the elderly in early rehabilitation after total knee arthroplasty. J Phys Ther Sci, 2012, 24: 27-30. [CrossRef]

24) Maruyama $T$, Sawada $Y$, Kubo S, et al.: Postoperative changes in knee joint function of total knee arthroplasty patients. J Phys Ther Sci, 2011, 23: 719-724. [CrossRef]

25) Williams A: Setting priorities in health care: an economist's view. J Bone Joint Surg Br, 1991, 73-B: 365-367. [Medline]

26) Blue Cross Blue Shield Association. Health care costs, understanding managed care act, 2004

27) Kramer JF, Speechley M, Bourne R, et al.: Comparison of clinic- and home-based rehabilitation programs after total knee arthroplasty. Clin Orthop Relat Res, 2003, (410): 225-234. [Medline] [CrossRef]

28) Mahomed NN, Koo Seen Lin MJ, Levesque J, et al.: Determinants and outcomes of inpatient versus home based rehabilitation following elective hip and knee replacement. J Rheumatol, 2000, 27: 1753-1758. [Medline] 